\title{
Article \\ Risk and Clinical Significance of Idiopathic Preterm Birth in Microvillus Inclusion Disease
}

\author{
Changsen Leng ${ }^{1,2,+}$, Yue Sun ${ }^{1,+}+\mathbb{C}$ and Sven C. D. van IJzendoorn ${ }^{1, *}$ \\ 1 Department of Biomedical Sciences of Cells and Systems, Centre for Liver, Digestive and Metabolic Disease, \\ University of Groningen, University Medical Centre Groningen, 9713 AV Groningen, The Netherlands; \\ lengchangsen@hotmail.com (C.L.); y.sun@umcg.nl (Y.S.) \\ 2 Department of Thoracic Surgery, Guangdong Esophageal Cancer Institute, State Key Laboratory of Oncology \\ in South China, Collaborative Innovation Centre for Cancer Medicine, Sun Yat-sen University Cancer Centre, \\ Guangzhou 510060, China \\ * Correspondence: s.c.d.van.ijzendoorn@umcg.nl \\ + These authors contributed equally.
}

Citation: Leng, C.; Sun, Y.;

van IJzendoorn, S.C.D. Risk and

Clinical Significance of Idiopathic Preterm Birth in Microvillus Inclusion Disease. J. Clin. Med. 2021, 10, 3935.

https://doi.org/10.3390/jcm10173935

Academic Editors: Katsunori Yoshida and Hidekazu Suzuki

Received: 1 July 2021

Accepted: 30 August 2021

Published: 31 August 2021

Publisher's Note: MDPI stays neutral with regard to jurisdictional claims in published maps and institutional affiliations.

Copyright: (c) 2021 by the authors. Licensee MDPI, Basel, Switzerland. This article is an open access article distributed under the terms and conditions of the Creative Commons Attribution (CC BY) license (https:// creativecommons.org/licenses/by/ $4.0 /)$.

\begin{abstract}
Microvillus inclusion disease (MVID) is a rare enteropathy caused by mutations in the MYO5B or STX3 gene. MVID is a disease that is difficult to manage with clinical heterogeneity. Therefore, knowledge about factors influencing MVID morbidity and mortality is urgently needed. Triggered by a recent study that reported a high percentage of preterm birth in twelve cases of MVID, we have conducted a comprehensive retrospective study involving 88 cases of MVID with reported gestational ages. We found that moderate to late preterm birth occurred in more than half of all cases, and this was particularly prominent in MYO5B-associated MVID. Preterm birth in MVID counterintuitively correlated with higher birth weight percentiles, and correlated with higher stool outputs and a significantly shorter average survival time. Data from this study thus demonstrate an increased risk of preterm birth in MYO5B-associated MVID, with a clinical impact on morbidity and mortality. Adverse effects associated with preterm birth should be taken into account in the care of children diagnosed with MVID. Documentation of gestational age may contribute to a better prognostic risk assessment in MVID.
\end{abstract}

Keywords: microvillus inclusion disease; MYO5B; STX3; preterm birth; premature birth; congenital microvillus atrophy; congenital diarrheal disorder; intrahepatic cholestasis; PFIC

\section{Introduction}

Microvillus inclusion disease (MVID) is a rare enteropathy [1,2]. MVID clinically presents with severe congenital intractable secretory diarrhea, malabsorption and failure to thrive [1,2]. MVID is an autosomal recessive disease associated with bi-allelic mutations in the MYO5B gene [3] or bi-allelic mutations in the STX3 gene [4] in $\sim 95 \%$ or $\sim 5 \%$ of cases, respectively [5,6]. Symptoms of MVID are also present in some patients diagnosed with familial hemophagocytic lymphohistiocytosis caused by mutations in the STXBP2 gene [5,7], but because of their distinctive hyper-inflammatory symptoms these patients are not diagnosed with MVID.

MVID is uniformly fatal if left untreated. Treatment is only supportive and involves life-long maintenance of nutrition and hydration with total parenteral nutrition (TPN). Prognosis is generally poor, and most patients die within one year after birth, mostly due to sepsis or liver disease [8]. With more case reports being published, it has become clear that the clinical presentation and course of MVID can be heterogeneous. Some patients could even be weaned off TPN [9-11]. Because MVID is a difficult to manage disease [12], more information is needed about factors that influence MVID morbidity and mortality.

Recently, Caralli and colleagues [13] noted a relatively high prevalence of preterm births in MVID when compared to other congenital diarrheal disorders. However, their 
report was based on only twelve cases. Worldwide, preterm birth-associated complications are the leading cause of death among young children [14]. Moreover, preterm birth is associated with gastrointestinal tract immaturity and growth failure, which are key features of MVID [1,15]. Therefore, more data are needed to confirm or refute the high prevalence of preterm birth in MVID, and, if confirmed, determine its significance for MVID morbidity and mortality.

\section{Methods}

\subsection{Collection of Case Reports}

To collect all published reports on cases of MVID, we searched EMBASE and MEDLINE databases using the following search strings: ((microvill* inclusion disease) OR (microvill* atrophy)) AND case report). Data from these cases were manually analyzed (using the 'find' tool in Adobe reader) with regard to preterm birth (defined as parturition prior to 37 weeks of gestation) [16], sex, birth weight, time of onset of diarrhea, stool volume, TPN dependency, neonatal respiratory distress, liver disease, polyhydramnios, gene mutations and survival (Supplemental Table S1).

\subsection{Statistics}

Odds ratios (OR) were calculated as measures of association. Statistical analyses included chi-square test with Yates correction to prevent the overestimation of statistical significance for small data, Pearson's correlations and Student's or Welch's two-tailed t-tests to determine statistical significance, assuming a priori statistical significance when $p<0.05$. The Mann-Whitney $\mathrm{U}$ test was used for non-normally distributed data sets. Levene's test was used to determine homogeneity of variances. The Shapiro-Wilk test was used to determine normality. Sex-corrected birth weight percentiles were calculated at https:/ / www.audipog.net/Courbes-morpho. Graphs were generated at https:/ / canva. com/graphs and with MS Excel (2103 (16.0.13901.20400)/accessed on 13 April 2021).

Due to the retrospective nature of this study, data were missing in several variables because of incomplete data recording. Because our aim was to simply describe and compare subgroups of patients with different gestational ages (i.e., preterm versus term), no method for missing data was utilized.

\section{Results}

\subsection{Increased Risk of Idiopathic Preterm Birth in MVID}

In this retrospective study, study subjects were retrieved from a recently published collection of 131 published MVID cases since 1978 [8], complemented with 44 more recently reported cases [11] and one additional case from the literature search. From this collection of 176 MVID patients, gestational age was documented in 88 cases (Supplemental Table S1) and on average was 35.6 weeks. Preterm birth occurred in 52\% $(46 / 88)$ of these cases without sex preference. This is significantly higher when compared to the world average of $10 \%$ (OR 9.42, 95\% CI 4.34-20.46, $p<0.0001)$. Of the preterm births in MVID, 91\% (42/46) were categorized as moderate to late preterm birth $\left(33^{+0}-36^{+6}\right.$ weeks gestation) (Figure $\left.1 \mathrm{~A}\right)$.

Of the preterm births in MVID for which the mode of delivery was documented, $84 \%$ $(27 / 32)$ were spontaneous (that is, without elective labor induction or cesarean section). Medically indicated factors linked to late preterm birth, such as intrahepatic cholestasis during pregnancy, maternal diabetes, placental abruption, placenta previa, hypertension, preeclampsia, intrauterine growth restriction or multiple gestation, were not or rarely reported. Polyhydramnios (defined as an excess amount of amniotic fluid) was reported in $22 \%(12 / 55)$ of MIVD patients, for which the presence or absence of polyhydramnios was documented. However, there was no significant difference in the occurrence of polyhydramnios between preterm and term births in $\operatorname{MVID}\left(X^{2}(1, N=54)=0.0443, p=0.83\right)$. 
A

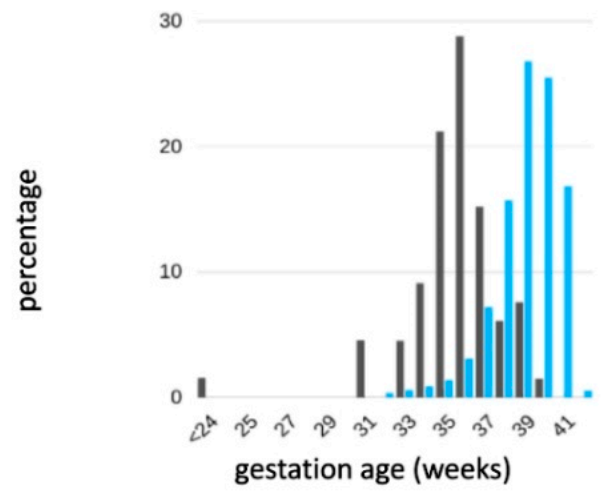

C

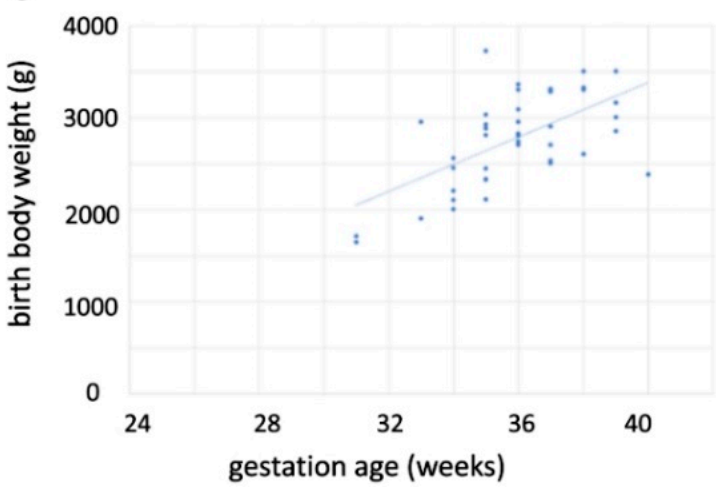

B

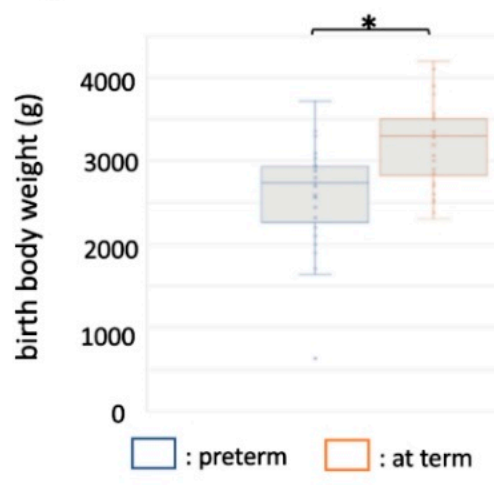

D

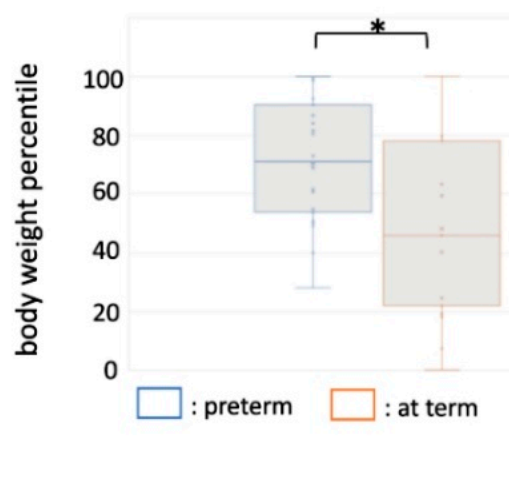

Figure 1. Preterm birth characteristics of MVID. (A) Distribution of gestational ages in MVID (black bars) versus population (blue bars). (B) Box-and-whisker plot showing average and mean body weights in MVID patients born preterm (blue) and at term (orange). (C) Correlation between gestational age and body weight in MVID. (D) Box-and-whisker plot showing average and mean body weight percentiles in MVID patients born preterm (blue) and at term (orange). ${ }^{*} p<0.05$. For exact $p$ values see text.

The average birth weight of MVID patients was significantly lower in preterm born patients $(2584 \pm 612 \mathrm{~g}$ versus $3191 \pm 485 \mathrm{~g}$ (mean $\pm \mathrm{SD})$ for preterm and term births, respectively; $t(62)=-4.36, p=0.00005)$ (Figure 1B). Gestational age positively correlated with birth weight (Figure 1C). Notably, for 58\% (19/33) of preterm MVID patients, the average birth weight was within the normal range (2500-4000 g regardless of gestational age). Moreover, when corrected for sex and gestation age, birth weight percentiles for preterm births were significantly higher when compared to term births $(70.1 \pm 19.9$ and $48.3 \pm 28.9$ (mean $\pm \mathrm{SD}$ ), respectively; $t(46)=2.96, p=0.005)$. Forty-one percent $(12 / 29)$ of preterm birth weights in MVID were above the 80th centile (for term MVID cases this percentage was $12 \%(2 / 17)$ ) (OR 5.29, 95\% CI 1.02-27.57, $p=0.048)$ (Figure 1D), albeit still considered as appropriate for gestational age.

Together, MVID is associated with an increased risk of idiopathic preterm birth and a therewith associated higher average birth weight percentile.

\subsection{Relationship between Preterm Birth and MVID-Causing Gene Mutations}

We next investigated whether preterm birth in MVID was associated with specific causative genes. No MVID patients with STX3 mutations were born preterm $[4,17,18]$, whereas $76 \%$ (16/21) of MVID patients with MYO5B mutations were born preterm (Figure 2). Hence, for the MVID patients where the gene mutation had been identified, the increased risk of preterm birth in MVID was restricted to patients with MYO5B mutations. 


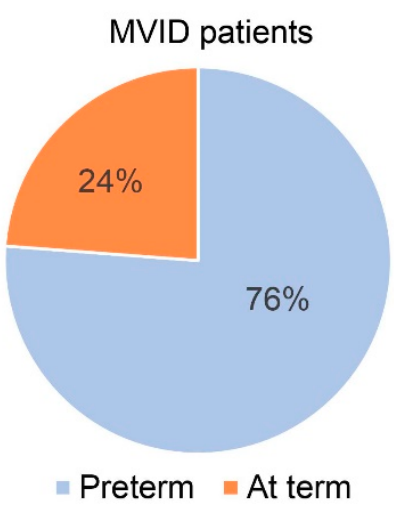

(A)

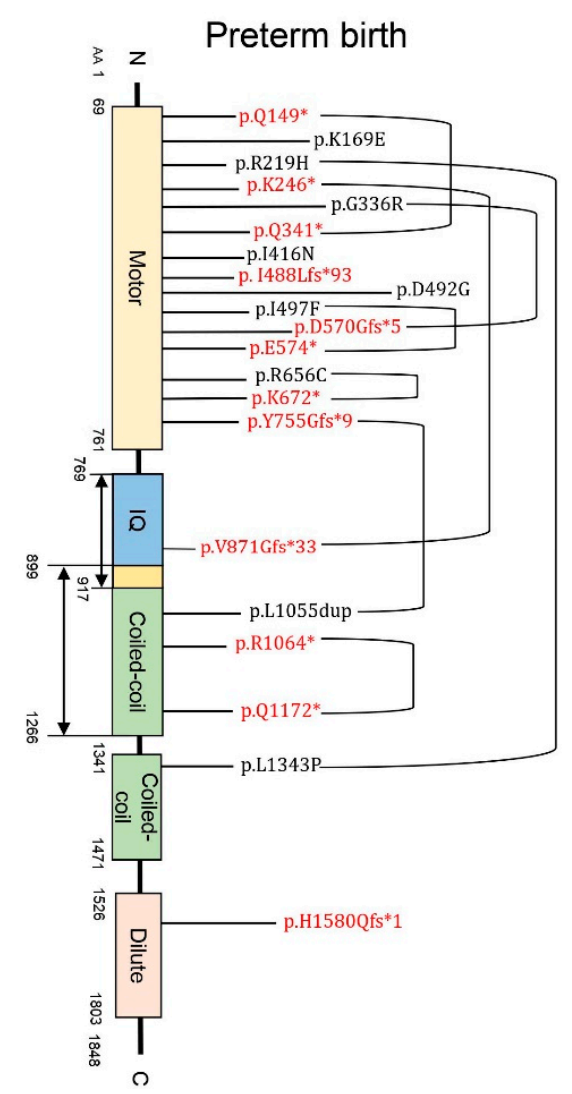

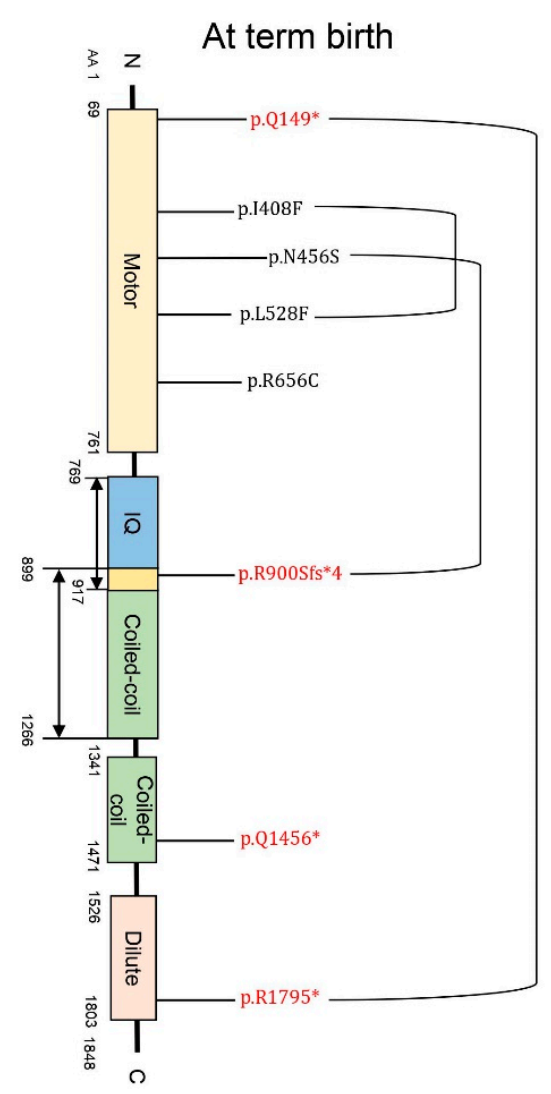

(B)

Figure 2. Relationship between $M Y O 5 B$ mutations and preterm birth in MVID. (A) Pie chart showing the percentage of preterm (blue) and at term (orange) births in cases of MVID associated with biallelic MYO5B mutations. (B) MYO5B mutations associated with preterm and at term births in MVID and the position of these mutation in the myosin $\mathrm{Vb}$ protein. Mutations that give rise to a premature termination codon are shown in red; other mutations are shown in black. Brackets connecting mutations indicate that these mutations were identified in the same patient. The absence of a bracket indicates a homozygous mutation. Asterisks indicate premature truncation of the protein.

Bi-allelic MYO5B mutations, excluding bi-allelic nonsense and/or frameshift mutations that give rise to premature termination codons and/or loss of the RAB11A binding site in the encoded myosin $\mathrm{Vb}$ protein, were also found in 14 patients who displayed no or episodal intestinal symptoms and were diagnosed with progressive familial intrahepatic cholestasis (PFIC)-type $6[19,20]$. Notably, none of these PFIC6 patients were born preterm $[19,20]$.

These results indicate that preterm birth in MVID appeared restricted to patients with bi-allelic $M Y O 5 B$ mutations, but that not all bi-allelic $M Y O 5 B$ mutations increased the risk of preterm birth.

\subsection{The Impact of Preterm Birth on MVID Morbidity and Mortality}

Clinical characteristics of MVID, such as time of onset, extent of diarrhea, TPN dependency, intrahepatic cholestasis, neonatal respiratory distress and time of death display a poorly understood inter-patient heterogeneity $[8,11,21]$. We next addressed the relationship between these characteristics and preterm birth in MVID.

\subsubsection{Diarrhea and TPN Dependency}

Preterm born individuals have an immature gastrointestinal tract. Immaturity of the small intestine is a key feature of MVID, and is associated with a secretory phenotype [15]. There was no difference in the time of onset of diarrhea between preterm and term births $(t(70)=0.364, p=0.36)$, but a higher average stool output was observed in preterm 
births when compared to term births $(166.5 \pm 54$ versus $126.26 \pm 49.6 \mathrm{~mL} / \mathrm{kg} /$ day in preterm versus term births, respectively; $t(31)=-2.15, p=0.02$ ) (Figure 3A). All MVID patients required TPN, hence without correlation to gestational age at birth or birth weight percentile. The few reported patients that could be weaned off the TPN were all born at term $[9,10]$. Preterm birth in MVID thus may have influenced the extent of diarrhea and limited the chance to be weaned off TPN.

A

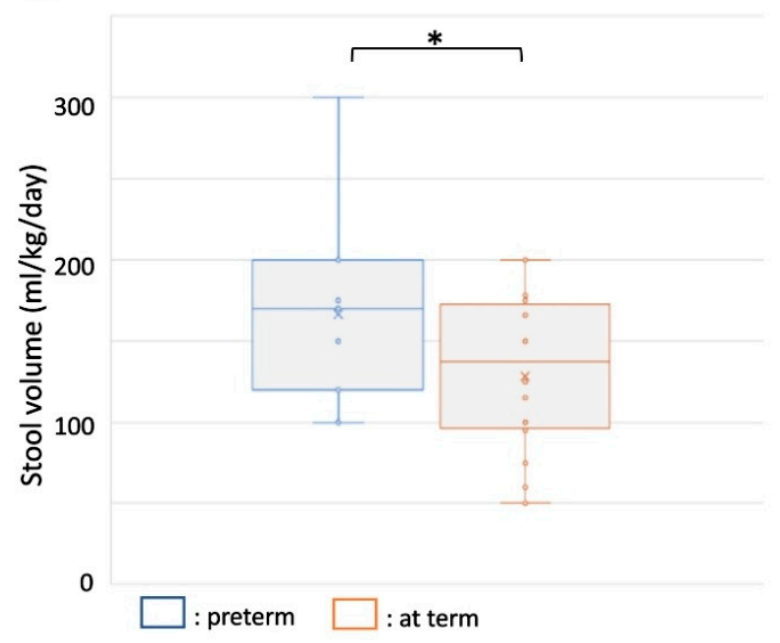

B

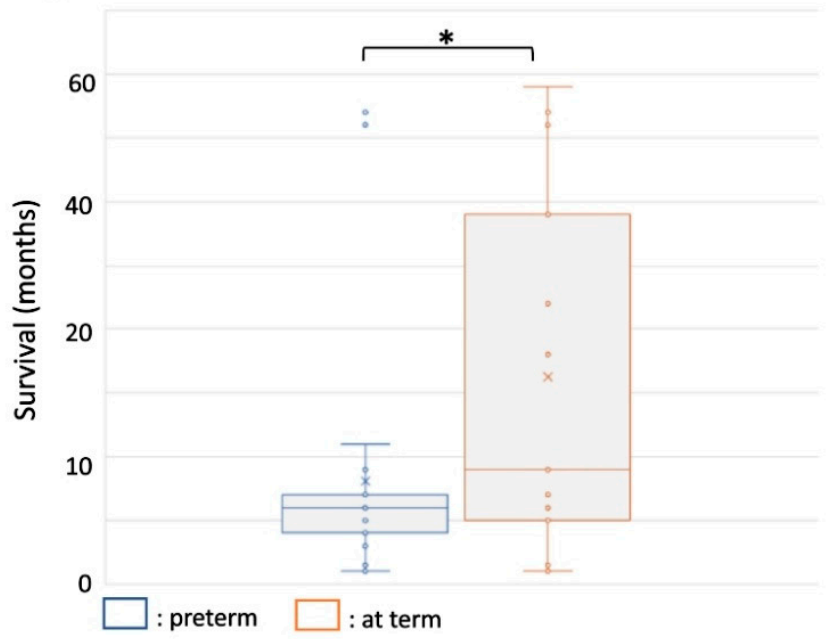

Figure 3. Stool volume and survival in MVID patients born preterm and at term. (A) Box-and-whisker plot showing average and mean stool volumes in MVID patients born preterm (blue) and at term (orange). (B) Box-and-whisker plot showing average and mean survival in MVID patients born preterm (blue) and at term (orange). ${ }^{*} p<0.05$ (for exact $p$ values see text).

\subsubsection{Respiratory Distress}

Neonatal respiratory distress has been reported in several cases of MVID, but how often it occurred in MVID has not been investigated. In our MVID case report collection, neonatal respiratory distress was reported in 16\% (14/88) of cases of MVID, often preceding the onset of diarrhea and requiring assisted ventilation. In the remaining 74 cases, there was no mention of respiratory distress, meaning that respiratory distress either did not occur or did occur but was not known to the authors. Notably, all but one of the fourteen respiratory distress cases were associated with preterm birth (range: 34-36 weeks), indicating that respiratory distress occurred in at least $28 \%$ (13/46) of preterm births in MVID.

\subsubsection{Cholestasis}

A life-threatening extra-intestinal symptom of MVID is intrahepatic cholestasis [21-23]. Intrahepatic cholestasis manifests in $~ 50 \%$ of all MVID patients [21]. The etiology of cholestasis in MVID is not clear, but may be caused by the MYO5B mutations carried by the patient and/or may be a complication of the TPN [21-24]. Although preterm birth in general is linked to a higher risk of neonatal hyperbillirubinia and jaundice due to liver immaturity, the percentage of MVID patients with reported liver disease or jaundice was similar in the preterm and term birth groups (liver disease reported in $55 \%(12 / 22)$ and $45 \%(10 / 22)$ of preterm and term births, respectively).

\subsubsection{Mortality}

We next addressed mortality. Of the documented deaths in the MVID cohort, preterm birth $(t(38)=-3.26, p=0.0329)$, but not birth weight $(r(27)=0.1499, p=0.46)$ or stool output $(r(34)=-0.045, p=0.79)$, was associated with a shorter average survival time (6.25 months for preterm births versus 16.31 months for at term births) (Figure 3B). 


\section{Discussion}

This retrospective study revealed moderate to late preterm birth in more than half of all reported MVID cases. This is $\sim 5$-fold higher when compared to the world average $(\sim 10 \%)$ [25]. On a cautionary note, this number is based on cases for which gestational age was reported $(50 \%(88 / 176)$ of all cases), and a reporting bias cannot be excluded. Nonetheless, if in the unlikely scenario that in all cases where gestational age was not reported patients would have been born at term, the percentage of preterm patients would be at least $26 \%(46 / 176)$, which is still significantly higher than the world average. MVID fetuses thus showed an increased odds of being born preterm.

Moderate to late preterm birth is generally associated with higher rates of infant morbidity and mortality when compared to full term birth [26]. A higher average stool volume in MVID was observed in the preterm birth group when compared to the at term birth group. Furthermore, a reduction in the average survival time was observed in the preterm birth group when compared to the at term birth group. Hence, moderate to late preterm birth appeared as a contributing factor with regard to MVID morbidity and mortality.

The gastrointestinal system is subject to rapid growth and maturation in the final weeks before birth. Consequently, moderate to late preterm birth is associated with immaturity of the gastrointestinal system. Preterm birth can be expected to contribute to, aggravate or complicate gastrointestinal symptoms in MVID neonates.

Neonatal respiratory distress was noted in at least one third of all reported moderate to late preterm MVID births. The risk of respiratory distress associated with preterm birth in general is well known, but it occurs predominantly in early preterm birth and much less in moderate to late preterm birth (declining from $98 \%$ to $5 \%$ in those born at 24 and 34 weeks of gestation, respectively [27]). The relatively high percentage of respiratory distress reported in moderate to late preterm MVID patients may therefore suggest that preterm MVID patients were at an increased risk of developing neonatal respiratory distress.

Why MVID patients were at risk of preterm birth is an outstanding question. There was no correlation between preterm birth in MVID and reported maternal risk factors or complications during pregnancy. Antenatal symptoms [28] occurred in almost onequarter of MVID cases, but were not different between the preterm and at term birth groups. Increased fetal growth has been shown to increase the risk of spontaneous late preterm birth $[29,30]$. Higher birth weight percentiles were observed in MVID patients who were born preterm, when compared to those born at term. Whether this was specific for MVID or a more general phenomenon associated with late preterm birth [29] remains to be determined.

Several maternal factors associated with preterm birth risk, such as maternal age, size or smoking behavior were not typically reported in published case studies. However, there is no reason to believe that these factors were unevenly distributed between parents of MVID patients and non-MVID patients. It is also unlikely that the high percentage of preterm birth in MVID was related to the patients' country of origin, as the range of average preterm birth percentages between high- and low-income countries is $9-12 \%$, respectively, and none of the reported MVID patients originated from world regions with the highest preterm birth rate [25].

MVID belongs to a subgroup of congenital diarrheal disorders [13,31]. These include, in addition to MVID, tufting enteropathies and trichohepatoenteric syndrome (THES). Caralli and colleagues reported a high percentage $(50 \%, 14 / 28)$ of preterm birth in THES [13]. In contrast to MVID, THES was independent of gestational age, associated with very to extremely low birth weight percentile, indicative of intrauterine growth restriction (IUGR) [13]. In addition to THES, congenital chloride losing diarrhea caused by SLC26A3 mutations was associated with very (29\%) and moderate to late $(59 \%)$ preterm birth, polyhydramnios and IUGR [32]. While loss of the SLC26A3 protein has been reported in the MVID intestine [33], MVID was not associated with IUGR but rather with increased fetal growth. Other congenital diarrheal disorders and enteropathies associated with enterocyte 
defects were not associated with preterm birth [13], suggesting that prenatal intestinal dysfunction as such does not appear to predispose to preterm birth.

Possibly, some MYO5B mutations may be independent risk factors for preterm birth. Little is known about genes associated with preterm birth [34]. Preterm birth was restricted to MVID patients with MYO5B mutations. We found no link between MYO5B and other genes associated with diseases with preterm birth as a phenotype (HP:0001622; Human Phenotype Ontology (https:/ /hpo.jax.org; accession date: 30 August 2021). Interestingly, $E B F 1$, which encodes a transcription factor for-among many others-MYO5B, was identified in a genome-wide association study searching for loci associated with gestation age and preterm birth [35]. As timing of delivery involves concerted actions of the fetus, uterus, decidua and placenta, it would be of interest to investigate the effect of fetal and/or maternal mutations in the MYO5B gene on embryonal and fetal development, and on the function of the placenta in which MYO5B is highly expressed (Human Protein Atlas: https:/ / www.proteinatlas.org/ENSG00000167306-MYO5B/tissue/placenta; accession date: 30 August 2021). Such studies may contribute to a better understanding of genetic and cell biological mechanisms that can lead to preterm birth.

In conclusion, we demonstrated a high percentage of idiopathic preterm births in MYO5B-associated MVID, and, moreover, put this finding in a clinical perspective with regard to MVID morbidity and mortality. Preterm birth and therewith associated adverse effects should thus be considered in the care of children diagnosed with MVID. Documentation of gestation age may contribute to a better prognostic risk assessment in MVID.

Supplementary Materials: The following are available online at https:/ / www.mdpi.com/article/10 $.3390 /$ jcm10173935/s1, Table S1: MVID case reports with documented gestation age.

Author Contributions: Conceptualization, S.C.D.v.I.; methodology, S.C.D.v.I., C.L. and Y.S.; formal analysis, S.C.D.v.I., C.L. and Y.S.; investigation, S.C.D.v.I., C.L. and Y.S.; resources, S.C.D.v.I., C.L. and Y.S.; data curation, S.C.D.v.I.; writing-original draft preparation, S.C.D.v.I., C.L. and Y.S.; writingreview and editing, S.C.D.v.I., C.L. and Y.S.; supervision, S.C.D.v.I.; project administration, S.C.D.v.I. All authors have read and agreed to the published version of the manuscript.

Funding: This research received no external funding.

Institutional Review Board Statement: Not applicable.

Informed Consent Statement: Not applicable.

Data Availability Statement: Data supporting reported results are published with this article.

Conflicts of Interest: The authors declare no conflict of interest.

\section{References}

1. Cutz, E.; Rhoads, J.M.; Drumm, B.; Sherman, P.M.; Durie, P.R.; Forstner, G.G. Microvillus Inclusion Disease: An Inherited Defect of Brush-Border Assembly and Differentiation. N. Engl. J. Med. 1989, 320, 646-651. [CrossRef] [PubMed]

2. Jayawardena, D.; Alrefai, W.A.; Dudeja, P.K.; Gill, R.K. Recent Advances in Understanding and Managing Malabsorption: Focus on Microvillus Inclusion Disease. F1000Research 2019, 8. [CrossRef]

3. Müller, T.; Hess, M.W.; Schiefermeier, N.; Pfaller, K.; Ebner, H.L.; Heinz-Erian, P.; Ponstingl, H.; Partsch, J.; Röllinghoff, B.; Köhler, H.; et al. MYO5B Mutations Cause Microvillus Inclusion Disease and Disrupt Epithelial Cell Polarity. Nat. Genet. 2008, 40, 1163-1165. [CrossRef]

4. Wiegerinck, C.L.; Janecke, A.R.; Schneeberger, K.; Vogel, G.F.; van Haaften-Visser, D.Y.; Escher, J.C.; Adam, R.; Thöni, C.E.; Pfaller, K.; Jordan, A.J.; et al. Loss of Syntaxin 3 Causes Variant Microvillus Inclusion Disease. Gastroenterology 2014, 147, 65-68.e10. [CrossRef] [PubMed]

5. Dhekne, H.S.; Pylypenko, O.; Overeem, A.W.; Zibouche, M.; Ferreira, R.J.; van der Velde, K.J.; Rings, E.H.H.M.; Posovszky, C.; van der Sluijs, P.; Swertz, M.A.; et al. MYO5B, STX3, and STXBP2 Mutations Reveal a Common Disease Mechanism That Unifies a Subset of Congenital Diarrheal Disorders: A Mutation Update. Hum. Mutat. 2018, 39, 333-344. [CrossRef] [PubMed]

6. $\quad$ van der Velde, K.J.; Dhekne, H.S.; Swertz, M.A.; Sirigu, S.; Ropars, V.; Vinke, P.C.; Rengaw, T.; van den Akker, P.C.; Rings, E.H.H.M.; Houdusse, A.; et al. An Overview and Online Registry of Microvillus Inclusion Disease Patients and Their MYO5B Mutations. Hum. Mutat. 2013, 34, 1597-1605. [CrossRef] 
7. Stepensky, P.; Bartram, J.; Barth, T.F.; Lehmberg, K.; Walther, P.; Amann, K.; Philips, A.D.; Beringer, O.; Zur Stadt, U.; Schulz, A.; et al. Persistent Defective Membrane Trafficking in Epithelial Cells of Patients with Familial Hemophagocytic Lymphohistiocytosis Type 5 Due to STXBP2/MUNC18-2 Mutations. Pediatr. Blood Cancer 2013, 60, 1215-1222. [CrossRef]

8. Leng, C.; Rings, E.H.H.M.; de Wildt, S.N.; van IJzendoorn, S.C.D. Pharmacological and Parenteral Nutrition-Based Interventions in Microvillus Inclusion Disease. J. Clin. Med. 2020, 10, 22. [CrossRef]

9. Perry, A.; Bensallah, H.; Martinez-Vinson, C.; Berrebi, D.; Arbeille, B.; Salomon, J.; Goulet, O.; Marinier, E.; Drunat, S.; Samson-Bouma, M.-E.; et al. Microvillous Atrophy: Atypical Presentations. J. Pediatr. Gastroenterol. Nutr. $2014,59,779-785$. [CrossRef] [PubMed]

10. Croft, N.M.; Howatson, A.G.; Ling, S.C.; Nairn, L.; Evans, T.J.; Weaver, L.T. Microvillous Inclusion Disease: An Evolving Condition. J. Pediatr. Gastroenterol. Nutr. 2000, 31, 185-189. [CrossRef]

11. Aldrian, D.; Vogel, G.F.; Frey, T.K.; Ayyıldız Civan, H.; Aksu, A.Ü.; Avitzur, Y.; Ramos Boluda, E.; Çakır, M.; Demir, A.M.; Deppisch, C.; et al. Congenital Diarrhea and Cholestatic Liver Disease: Phenotypic Spectrum Associated with MYO5B Mutations. J. Clin. Med. 2021, 10, 481. [CrossRef]

12. Badawy, A.; Elfadul, M.; Aziabi, M.; Ageel, H.I.; Aqeel, A. Challenges of Microvillus Inclusion Disease in the NICU. Neoreviews 2020, 21, e600-e604. [CrossRef]

13. Caralli, M.; Roman, C.; Coste, M.-E.; Roquelaure, B.; Buffat, C.; Bourgeois, P.; Badens, C.; Fabre, A. Genetic Enteropathies Linked to Epithelial Structural Abnormalities and Enteroendocrine Deficiency: A Systematic Review. J. Pediatr. Gastroenterol. Nutr. 2021, 72, 826-832. [CrossRef]

14. Liu, L.; Oza, S.; Hogan, D.; Chu, Y.; Perin, J.; Zhu, J.; Lawn, J.E.; Cousens, S.; Mathers, C.; Black, R.E. Global, Regional, and National Causes of under-5 Mortality in 2000-15: An Updated Systematic Analysis with Implications for the Sustainable Development Goals. Lancet 2016, 388, 3027-3035. [CrossRef]

15. Thoeni, C.E.; Vogel, G.F.; Tancevski, I.; Geley, S.; Lechner, S.; Pfaller, K.; Hess, M.W.; Müller, T.; Janecke, A.R.; Avitzur, Y.; et al. Microvillus Inclusion Disease: Loss of Myosin vb Disrupts Intracellular Traffic and Cell Polarity. Traffic 2014, 15, 22-42. [CrossRef] [PubMed]

16. Quinn, J.-A.; Munoz, F.M.; Gonik, B.; Frau, L.; Cutland, C.; Mallett-Moore, T.; Kissou, A.; Wittke, F.; Das, M.; Nunes, T.; et al. Preterm Birth: Case Definition \& Guidelines for Data Collection, Analysis, and Presentation of Immunisation Safety Data. Vaccine 2016, 34, 6047-6056. [CrossRef]

17. Julia, J.; Shui, V.; Mittal, N.; Heim-Hall, J.; Blanco, C.L. Microvillus Inclusion Disease, a Diagnosis to Consider When Abnormal Stools and Neurological Impairments Run Together Due to a Rare Syntaxin 3 Gene Mutation. J. Neonatal. Perinatal. Med. 2019, 12, 313-319. [CrossRef] [PubMed]

18. Alsaleem, B.M.R.; Ahmed, A.B.M.; Fageeh, M.A. Microvillus Inclusion Disease Variant in an Infant with Intractable Diarrhea. Case Rep. Gastroenterol. 2017, 11, 647-651. [CrossRef]

19. Qiu, Y.-L.; Gong, J.-Y.; Feng, J.-Y.; Wang, R.-X.; Han, J.; Liu, T.; Lu, Y.; Li, L.-T.; Zhang, M.-H.; Sheps, J.A.; et al. Defects in Myosin VB Are Associated with a Spectrum of Previously Undiagnosed Low $\gamma$-Glutamyltransferase Cholestasis. Hepatology 2017, 65, 1655-1669. [CrossRef]

20. Gonzales, E.; Taylor, S.A.; Davit-Spraul, A.; Thébaut, A.; Thomassin, N.; Guettier, C.; Whitington, P.F.; Jacquemin, E. MYO5B Mutations Cause Cholestasis with Normal Serum Gamma-Glutamyl Transferase Activity in Children without Microvillous Inclusion Disease. Hepatology 2017, 65, 164-173. [CrossRef] [PubMed]

21. van IJzendoorn, S.C.D.; Li, Q.; Qiu, Y.-L.; Wang, J.-S.; Overeem, A.W. Unequal Effects of Myosin 5B Mutations in Liver and Intestine Determine the Clinical Presentation of Low-Gamma-Glutamyltransferase Cholestasis. Hepatology 2020, 72, $1461-1468$. [CrossRef] [PubMed]

22. Girard, M.; Lacaille, F.; Verkarre, V.; Mategot, R.; Feldmann, G.; Grodet, A.; Sauvat, F.; Irtan, S.; Davit-Spraul, A.; Jacquemin, E.; et al. MYO5B and Bile Salt Export Pump Contribute to Cholestatic Liver Disorder in Microvillous Inclusion Disease. Hepatology 2014, 60, 301-310. [CrossRef] [PubMed]

23. Halac, U.; Lacaille, F.; Joly, F.; Hugot, J.-P.; Talbotec, C.; Colomb, V.; Ruemmele, F.M.; Goulet, O. Microvillous Inclusion Disease: How to Improve the Prognosis of a Severe Congenital Enterocyte Disorder. J. Pediatr. Gastroenterol. Nutr. 2011, 52, 460-465. [CrossRef] [PubMed]

24. Li, Q.; Sun, Y.; van IJzendoorn, S.C.D. A Link between Intrahepatic Cholestasis and Genetic Variations in Intracellular Trafficking Regulators. Biology 2021, 10, 119. [CrossRef]

25. Blencowe, H.; Cousens, S.; Oestergaard, M.Z.; Chou, D.; Moller, A.-B.; Narwal, R.; Adler, A.; Vera Garcia, C.; Rohde, S.; Say, L.; et al. National, Regional, and Worldwide Estimates of Preterm Birth Rates in the Year 2010 with Time Trends since 1990 for Selected Countries: A Systematic Analysis and Implications. Lancet 2012, 379, 2162-2172. [CrossRef]

26. Raju, T.N.K. The “Late Preterm" Birth-Ten Years Later. Pediatrics 2017, 139, e20163331. [CrossRef] [PubMed]

27. Yadav, S.; Lee, B.; Kamity, R. Neonatal Respiratory Distress Syndrome. In StatPearls; StatPearls Publishing: Treasure Island, FL, USA, 2021.

28. Many, A.; Hill, L.M.; Lazebnik, N.; Martin, J.G. The Association between Polyhydramnios and Preterm Delivery. Obstet. Gynecol. 1995, 86, 389-391. [CrossRef]

29. Lampl, M.; Kusanovic, J.P.; Erez, O.; Espinoza, J.; Gotsch, F.; Goncalves, L.; Hassan, S.; Gomez, R.; Nien, J.K.; Frongillo, E.A.; et al. Early Rapid Growth, Early Birth: Accelerated Fetal Growth and Spontaneous Late Preterm Birth. Am. J. Hum. Biol. 2009, 21, 141-150. [CrossRef] 
30. Elenis, E.; Wikström, A.-K.; Simic, M. Accelerated Fetal Growth in Early Pregnancy and Risk of Preterm Birth: A Prospective Cohort Study. BMC Pregnancy Childbirth 2020, 20, 764. [CrossRef]

31. Overeem, A.W.; Posovszky, C.; Rings, E.H.M.M.; Giepmans, B.N.G.; van IJzendoorn, S.C.D. The Role of Enterocyte Defects in the Pathogenesis of Congenital Diarrheal Disorders. Dis. Model. Mech. 2016, 9, 1-12. [CrossRef]

32. Wedenoja, S.; Höglund, P.; Holmberg, C. Review Article: The Clinical Management of Congenital Chloride Diarrhoea. Aliment. Pharmacol. Ther. 2010, 31, 477-485. [CrossRef] [PubMed]

33. Kravtsov, D.V.; Ahsan, M.K.; Kumari, V.; van Ijzendoorn, S.C.D.; Reyes-Mugica, M.; Kumar, A.; Gujral, T.; Dudeja, P.K.; Ameen, N.A. Identification of Intestinal Ion Transport Defects in Microvillus Inclusion Disease. Am. J. Physiol. Gastrointest. Liver Physiol. 2016, 311, G142-G155. [CrossRef] [PubMed]

34. Strauss, J.F.; Romero, R.; Gomez-Lopez, N.; Haymond-Thornburg, H.; Modi, B.P.; Teves, M.E.; Pearson, L.N.; York, T.P.; Schenkein, H.A. Spontaneous Preterm Birth: Advances toward the Discovery of Genetic Predisposition. Am. J. Obstet. Gynecol. 2018, 218, 294-314.e2. [CrossRef] [PubMed]

35. Zhang, G.; Feenstra, B.; Bacelis, J.; Liu, X.; Muglia, L.M.; Juodakis, J.; Miller, D.E.; Litterman, N.; Jiang, P.-P.; Russell, L.; et al. Genetic Associations with Gestational Duration and Spontaneous Preterm Birth. N. Engl. J. Med. 2017, 377, 1156-1167. [CrossRef] 